\title{
REDESCRIÇÃO DE HYALELLA PERNIX (MOREIRA) \\ (AMPHIPODA - HYALELLIDAE) COM DISCUSSÃO DE SEU SINONIMO H. CURVISPINA SHOEMAKER
}

VANIA FILIPPI GOULART C. PEREIRA

\begin{abstract}
Hyalella is widely distributed in the Americas. Until the present moment around 30 species have been identified.

Hyalella curvispina Shoemaker is treated as synonynous with Hyalella pernix (Moreira) due to the very strong similarities found in both species: they have in common an outstanding curved spine on the inner ramus of uropod 1 of the male. This is considered the main characteristic of $\mathrm{H}$. curvispina.

With the species already known and the synonymy treated here a total of 29 species of Hyalella is reached. It would seem that H. pernix is the most widespread species in Brazil and in South America as a whole.
\end{abstract}

\section{INTRODUÇÃO}

O gênero Hyalella acha-se distribuído largamente nas Américas e apresenta, até a presente data, cerca de 30 espécies.

Moreira (1903) descreveu Allorchestes pernix sp. n., um anfípodo de água doce encontrado a $2.240 \mathrm{~m}$ de altitude, no Planalto de Itatiaia, Estado do Rio de Janeiro, na realidade um típico representante do gênero Hyalella, conforme foi reconhecido por Stebbing (1906) no estudo taxonômico que realizou sobre anfípodos Gammaridea, no qual transferiu Allorchestes pernix para o gênero Hyalella.

Schoemaker (1942) descreveu Hyalella curvispina sp. n., coletada no Rio Grande do Sul, Brasil.

Schellenberg (1943) descreveu uma espécie nova, H. simplex, de Punta Arenas, Chile, e estabeleceu a forma cangallensis para exemplares provenientes do Peru.

Oliveira (1953), num estudo sobre anfípodos do Rio de Janeiro, apresenta uma chave para as espécies do gênero Hyalella verificadas no Brasil, e fornece descrição detalhada de Hyalella simplex f. cangallensis, que ele coloca na sinonímia da primeira.

Como a descrição de Moreira tem precedência sobre a de Shoemaker, o nome válido dessa espécie deve ser, doravante, Hyalella pernix.

Com as espécies já conhecidas e a sinonímia aqui tratada, perfaz-se um total de 29 espécies do gênero Hyalella, sendo que $H$. pernix parece ser a espécie mais largamente distribuída na América do Sul e Brasil.

\section{Hyalella pernix (Moreira)}

(Figs. 1-34)

Allorchestes pernix Moreira, 1903: 187.

Hyalella pernix; Stebbing, 1906: 736; Barnard, 1958: 79; Holsinger, 1981: 39. Hyalella knickerbockeri; Schellenberg, 1931: 227 [não H. knickerbockeri (Bate) $=H$. azteca (Saussure)].

Hyalella curvispina Shoemaker, 1942: 79 - Barnard, 1958: 79; Cavalieri, 1968:

116; Holsinger, 1981: 39. 
Hyalella simplex f. cangallensis Schellenberg, 1943: 201.

Hyalella curvispina f. cangallensis; Oliveira, 1953: 347.

Localidade-tipo: Lagoa Esgotada, Itatiaia, RJ.

Macho: os exemplares estudados medem de 2,5 a $9,5 \mathrm{~mm}$ e a cor apresenta-se variando do incolor ao castanho muito escuro. Olhos reniformes ou ovais. Cabeça tão longa quanto o $1 .^{\circ}$ somito do pereon mais a metade do $2 .^{\circ}$. Placas coxais distalmente arredondadas, sendo que a $4 .^{\circ}$ é maior que as 3 primeiras. Os somitos 1 a 3 do pleon aumentam gradualmente de tamanho, e apresentam os ângulos póstero-laterais do $2 .^{\circ}$ e $3 .^{\circ}$ somitos, agudos (Fig. 1). Brânquias normais muito desenvolvidas, presentes do $10^{\circ}$ ao $7 .^{\circ}$ apêndices torácicos, sendo que as do $1 .^{\circ}$ e $7 .^{\circ}$ são pequenas e finas; brânquias acessórias presentes do $2 .^{\circ}$ ao $6 .^{\circ}$ apêndices torácicos (Figs. 2, 3, 4, 5, 6, 18).

Antena 1 - medindo de 1,7 a $3,0 \mathrm{~mm}$ nos exemplares estudados; menor que a antena 2 , com cerca de $2 / 3$ do comprimento desta; atingindo o comprimento da cabeça, os 3 somitos e metade do $4 .^{\circ}$ somito do pereon. Pedúnculo com artículos diminuindo gradualmente em comprimento do $10^{\circ}$ ao último, pouco maior que a metade do comprimento do flagelo. Flagelo com cerca de 12 artículos, providos de pequenas cerdas em suas articulações (Fig. 7).

Antena 2 - medindo de 1,0 a $3,0 \mathrm{~mm}$ nos exemplares estudados; cerca da metade do comprimento total do corpo (cabeça ao télson, inclusive). Pedúnculo com algumas cerdas, o artículo terminal do mesmo comprimento que os dois precedentes. Flagelo quase duas vezes mais longo que o pedúnculo, com cerca de 14 artículos, provido de cerdas em suas articulações (Fig. 8).

Lábio superior - de contorno arredondado e delicados pêlos em sua extremidade distal (Fig. 9).

Lábio inferior - bilobado, com pêlos que se inclinam para o centro, em sua extremidade distal (Fig. 10).

Mandíbula - processo incisivo bem desenvolvido e denteado, apresentando na base 3 cerdas longas e plumosas, 1 curta e plumosa e algumas simples; processo molar grande com um tufo de cerdas na margem anterior (Fig. 11).

Maxila 1 - com ramo interno cerca de 3 vezes e meio mais longo que largo, e cerca de metade do comprimento do ramo externo, com ápice truncado portando duas longas cerdas plumosas; ramo externo largo, provido apicalmente de 9 espinhos, todos pectinados com exceção do mais externo; palpo pequeno, uniarticulado, com numerosas pequenas cerdas e portando em seu ápice um diminuto espinho (Fig. 12).

Maxila 2 - ramo externo ligeiramente maior que o interno, portando apicalmente numerosas cerdas simples, longas e curvas e pequenas cerdas nas laterais; ramo interno com numerosas cerdas simples, entremeadas de cerdas bipectinadas, além de 2 cerdas plumosas na margem superior interna e pequenas cerdas em ambas as margens (Fig. 13).

Maxilípede - lâmina interna da base com margem distal truncada, portando 3 dentes curtos, o mais externo um pouco maior, tendo entre eles pequenas cerdas bipectinadas; em sua margem interna há uma fileira de 5 cerdas plumosas e algumas pequenas cerdas simples. Lâmina do ísquio menor que a da base, com numerosas cerdas simples em suas margens distal e interna. Palpo com 3 artículos, sendo que o mero apresenta a margem distal muito oblíqua; própode com muitas cerdas longas nas margens distal e interna, sendo que há 6 cerdas unipectinadas na margem distal; dátilo duas vezes mais longo que largo, apresentando distalmente 4 cerdas simples e um longo espinho unipectinado em seu ápice (Fig. 14).

Gnatópode 1 - bem menor que o 2. Própode pouco mais longo que largo apresentando em seu lado interno, próximo à palma, uma fileira oblíqua de 6 cerdas bifurcadas plumosas e acima destas, alguns espinhos curtos espalhados; extremidade distal da margem anterior com um tufo de 9 cerdas longas e simples e, próximo a esta, no lado interno, existem numerosas escamas pectinadas e 3 cerdas simples; no terço superior, próximo à extremidade distal do lado interno, aparecem numerosas escamas pectinadas e uma cerda sim- 
ples; na extremidade distal da margem posterior há um lobo que porta um espinho longo farpado e um espinho curto cônico. Palma pouco convexa, serrilhada e portando cerdas de comprimento variável. Lado externo do própode com 4 cerdas próximas à palma. Dátilo pouco menor que a palma e adaptando-se bem a esta; superfície superior com uma fileira de escamas pectinadas, e superfície inferior com pequenos espínulos e um espinho. Carpo do mesmo comprimento que o própode, com extremidade distal anterior truncada e portando algumas cerdas simples e outras bipectinadas, e com um lobo relativamente desenvolvido, que apresenta uma fileira de cerdas submarginais plumosas, margem denteada e pectinada e superfície interna com escamas pectinadas; na base do lobo há 4 cerdas plumosas. Mero portando 6 cerdas e poucas escamas pectinadas, próximo à extremidade distal da margem posterior. Isquio de mesmo tamanho que o mero, tendo na extremidade distal da margem posterior algumas cerdas muito curtas e outras longas e farpadas. Base relativamente larga e pouco longa, com cerdas simples na extremidade distal da margem posterior e 2 farpadas ao longo do artículo (Figs. 15, 16, 17).

Gnatópode 2 - própode robusto, com lado interno apresentando na extremidade distal da margem anterior um tufo com cerca de 6 cerdas pouco longas e simples, e uma cerda simples em seu terço distal; margem posterior com pequenas cerdas e escamas pectinadas, próximas ao lobo da extremidade distal; este lobo porta 2 espinhos farpados; alguns pequenos espinhos aparecem próximos à palma que é oblíqua, regularmente convexa e revestida por pequenos espinhos e 2 destacados espinhos farpados. Dátilo liso, mais curto que a palma, mostrando em grande aumento, a superfície inferior ondulada e com pequenos espinhos; quando fechado, adapta-se perfeitamente à palma. Carpo cupuliforme, apresentando margem denteada e cerdas plumosas. Mero e ísquio com cerdas em suas extremidades distais da margem posterior, sendo que o comprimento do mero é um pouco maior que o do ísquio. Base com cerca de 8 cerdas na margem posterior e 4 na extremidade distal (Figs. 18, 19).

Pleópodes - com ramos bem mais longos que os respectivos pedúnculos, fortemente revestidos de espinhos nos diferentes artículos (Figs. 20, 21, 22, 23 e 24).

Pleópodes - com ramos bem mais longos que os respectivos pedúnculos, e apresentando cerdas plumosas.

Urópode 1 - pedúnculo pouco mais longo que os ramos, portando 4 espinhos farpados em sua margem interna. Ramo interno com 2 espinhos farpados na margem interna; ápice com 1 espinho curvo grande, 3 a 4 pequenos e 1 a 2 longos e retos. Ramo externo pouco menor que o interno, com 3 espinhos farpados na margem interna e 4 no ápice, sendo 2 curtos e 2 longos (Figs. $25,26)$.

Urópode 2 - pedúnculo do mesmo comprimento que o ramo interno, apresentando 4 espinhos farpados na margem interna. Ramo externo um pouco menor que o interno, com 2 espinhos farpados na margem interna e 4 apicais, sendo 2 curtos e 2 longos. Ramo interno com 2 espinhos farpados na margem interna e apresentando no ápice 3 espinhos curtos e 3 longos (Fig. 27).

Urópode 3 - pedúnculo de igual comprimento do ramo único, apresentando 3 longos e farpados espinhos e um curto e simples na extremidade distal externa; a extremidade distal interna apresenta um único espinho simples. Ramo com seu ápice truncado, portando na extremidade um espinho curto e outros 5 longos, finos e simples (Fig. 28).

Télson - tão longo quanto largo, com extremidade distal mais estreita que a base, portando em cada margem 2 espinhos, que podem ser um longo e um muito curto ou os 2 longos, e logo abaixo destes há, de cada lado, 3 curtas e delicadas cerdas (Fig. 29).

Fêmea: nos exemplares estudados o comprimento varia de 1,5 a 4,0 mm. Cada fêmea porta cerca de 18 ovos arredondados (Fig. 30). Semelhante ao macho, com exceção dos gnatópodes 1 e 2, e urópode 1.

Gnatópode 1 - com base, ísquio, mero e carpo semelhante aos do macho. Própode com algumas pequenas diferenças: relativamente mais estreito, com 
margem distal transversa, mais larga que a margem proximal; lado interno com uma fileira oblíqua de 5 cerdas bifurcadas e plumosas e, no terço distal, escamas pectinadas; palma com pequenos espinhos em toda sua extensão, entremeados por espinhos um pouco maiores e portando 2 fortes espinhos farpados na extremidade posterior; lado externo com 3 cerdas simples, próximas à margem distal e à articulação do dátilo. Dátilo com escamas pectinadas na sua margem superior, e espinhos distribuídos na sua margem inferior (Fig. 31).

Gnatópode 2 - própode semelhante ao do gnatópode 1 da fêmea, porém um pouco mais delgado; margem posterior com terço distal do lado interno com numerosas escamas pectinadas e 3 cerdas bifurcadas e plumosas dispostas em diagonal; lado externo com 2 grupos de cerdas próximas à palma, sendo um com 3 e outro com 4 cerdas. Dátilo adaptando-se bem à palma, com escamas pectinadas e espinhos (Figs. 32, 33, 34).

Urópode 1 - sem o destacado espinho curvo no ápice do ramo interno, como observado no macho.

\section{MATERIAL ESTUDADO}

1 - 23 espécimes, sendo 16 fêmeas (10 ovadas) e 7 machos. Lagoa Feia, Formosa, GO; Exp. Formosa col. - 20.7.1960; reg. n. ${ }^{\circ} 89 / 60$.

2 - 16 espécimes, sendo 13 fêmeas e 3 machos. Lagoa Esgotada, Itatiaia, RJ; Vania G. Pereira col. - 25.5.1976, 02.02.1981; alt. $2.240 \mathrm{~m}$; prof. 1,20 m.

3 - 53 espécimes, sendo 31 fêmeas e 22 machos. Estrada do Albordão, Taim, RS; Edma M. O. Ferronato col. - 04.7.1976.

4 - 2 espécimes, sendo 1 fêmea e 1 macho. Lagoa Feia, em Ponta Grossa dos Fidalgos, Campos, RJ.

5 - 71 espécimes, sendo 40 fêmeas e 31 machos; com muitos animais em acasalamento. Bituruna, PR; Starwiask col. - 01.1963; em lagoa permanente.

6 - 3 espécimes, sendo 2 fêmeas e 1 macho. Curitiba, PR; V. Santos col. - 08.01.1970, em brejo pequeno.

\section{DISTRIBUIÇÃO GEOGRÃFICA}

Equador, Peru, Uruguai, Chile, Argentina e Brasil (Rio Grande do Sul, Rio de Janeiro, Goiás e Paraná).

\section{DISCUSSÃO}

A espécie foi descrita em 1903 por Carlos Moreira, que a colocou no gênero Allorchestes, hoje constituído apenas por espécies marinhas, tendo sido transferido para o gênero Hyalella por Stebbing (1906). Os espécimes examinados pelo autor, provenientes da Lagoa Esgotada, Itatiaia, Estado do Rio de Janeiro, acham-se perdidos.

A descrição original carece de detalhes importantes para melhor caracterização e a espécie não foi reestudada até a presente data.

A captura de numerosos exemplares na Lagoa Esgotada (localidade-tipo) permitiu uma melhor caracterização da espécie e a constatação de sua ampla distribuição geográfica no Brasil, pelo exame de material proveniente de várias regiões do país. Por outro lado, a presença em Hyalella pernix de um destacado espinho curvo no ramo interno do urópode 1 do macho, característico de $H$. curvispina Shoemaker, 1942, e de outros detalhes morfológicos semelhantes, levam à conclusão de que esta última deve ser colocada na sinonímia da primeira.

Sob o nome de $H$. curvispina a espécie tem sido referida em outros países da América do Sul.

Os exemplares examinados do Brasil e as referências na literatura dão conta das grandes variações intra-específicas observadas quanto à pigmentação do corpo, tamanho dos adultos, número e posição dos fâneros. 


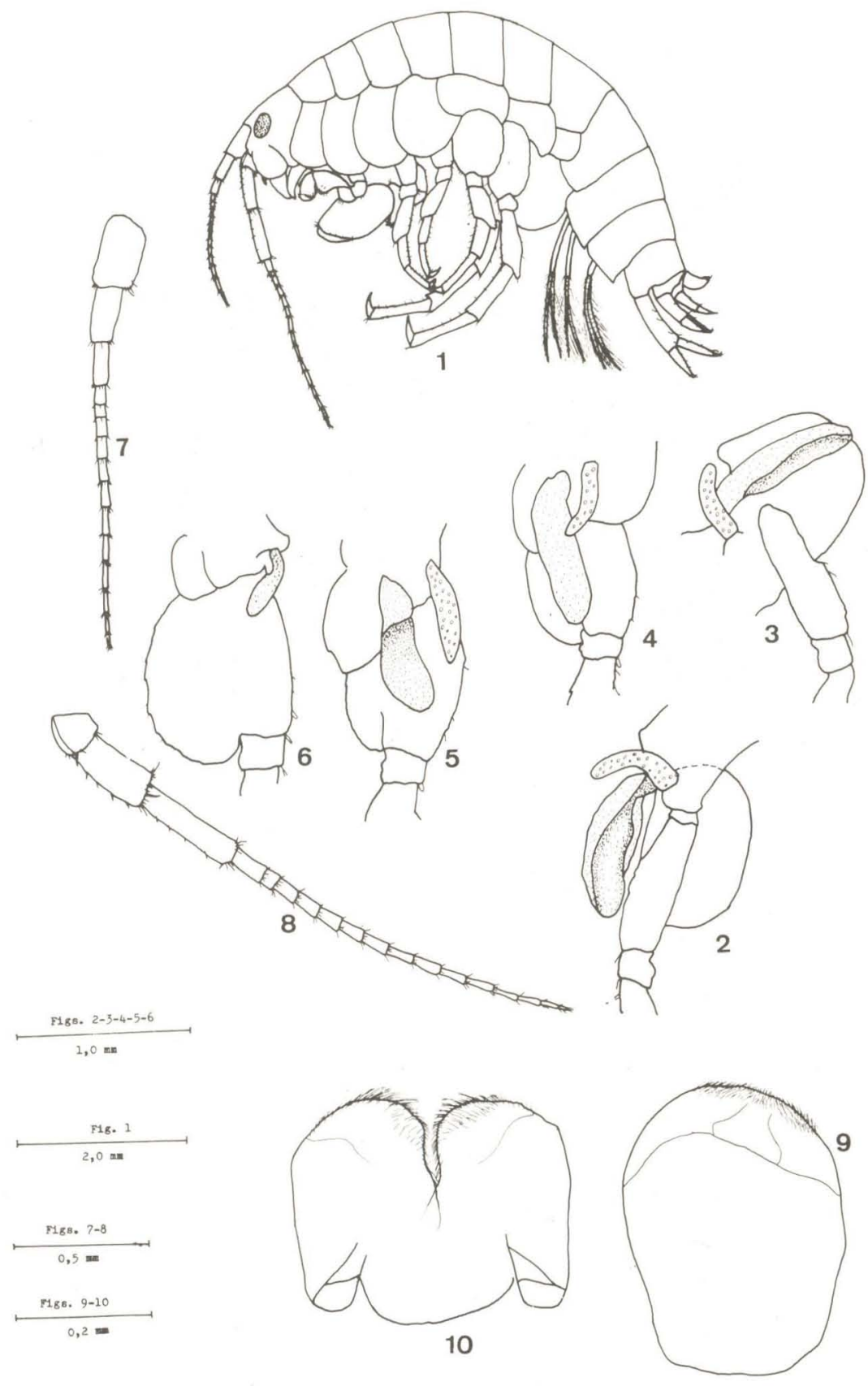

Hyalella pernix (Moreira), macho: Fig. 1 - Animal inteiro (vista lateral); Fig. 2 - Brânquias do pereópode 1; Fig. 3 - Brânquias do pereópode 2; Fig. 4 - Brânquias do pereópode 3; - Fig. 5 - Brânquias do pereópode 4; Fig. 6 - Brânquias do pereópode 5; Fig. 7 - Antena 1; Fig. 8 - Antena 2; Fig. 9 - Lábio superior; Fig. 10 - Lábio inferior. 

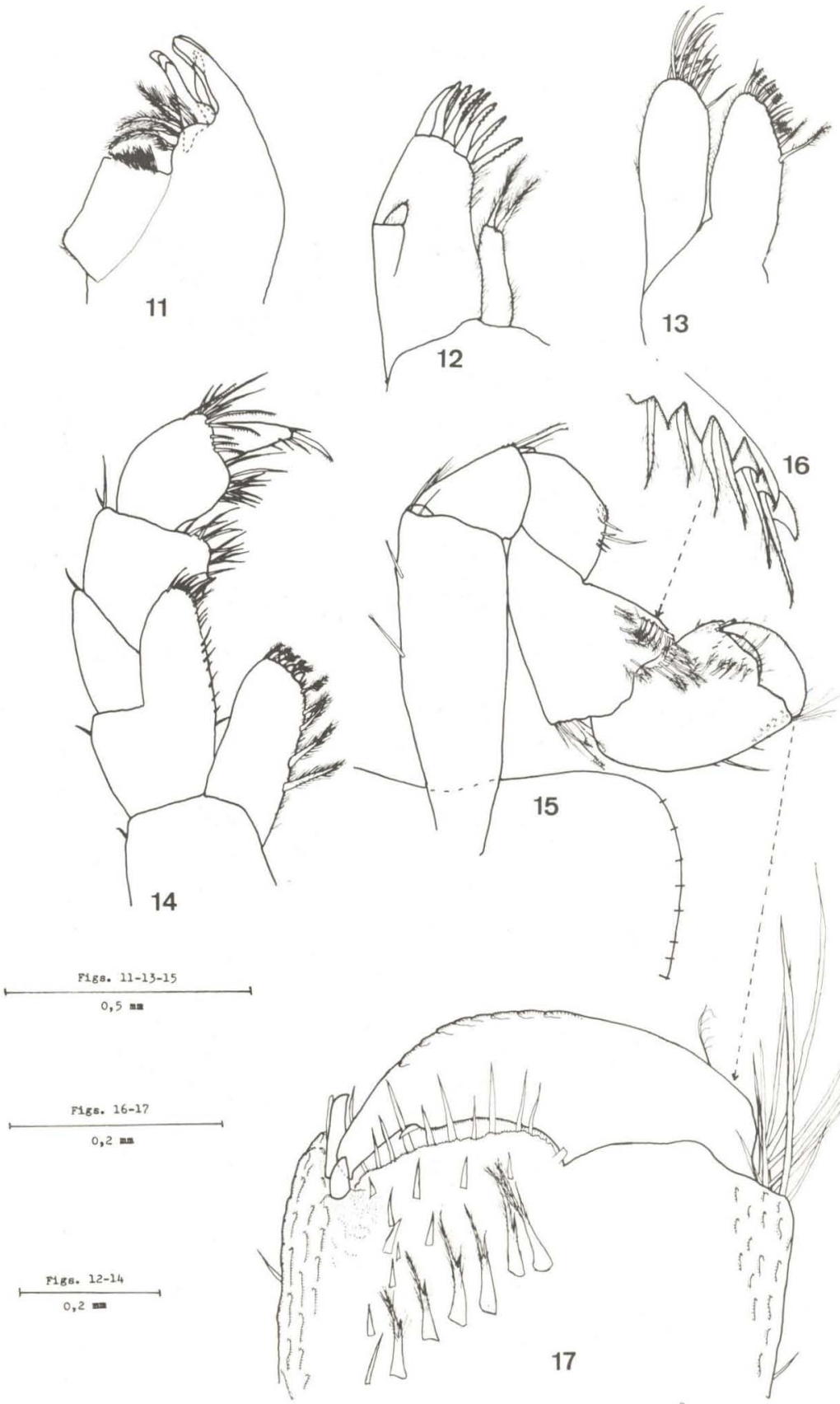

Hyalella pernix (Moreira), macho: Fig. 11 - Mandíbula; Fig. 12 - Maxila 1; Fig. 13 - Maxila 2; Fig. 14 - Maxilípede; Fig. 15 - Gnatópode 1 (lado interno); Fig. 16 - Lobo do carpo do gnatópode 1 (lado externo): Fig. 17 Dátilo e terço distal do própode do gnatópode 1 (lado interno). 

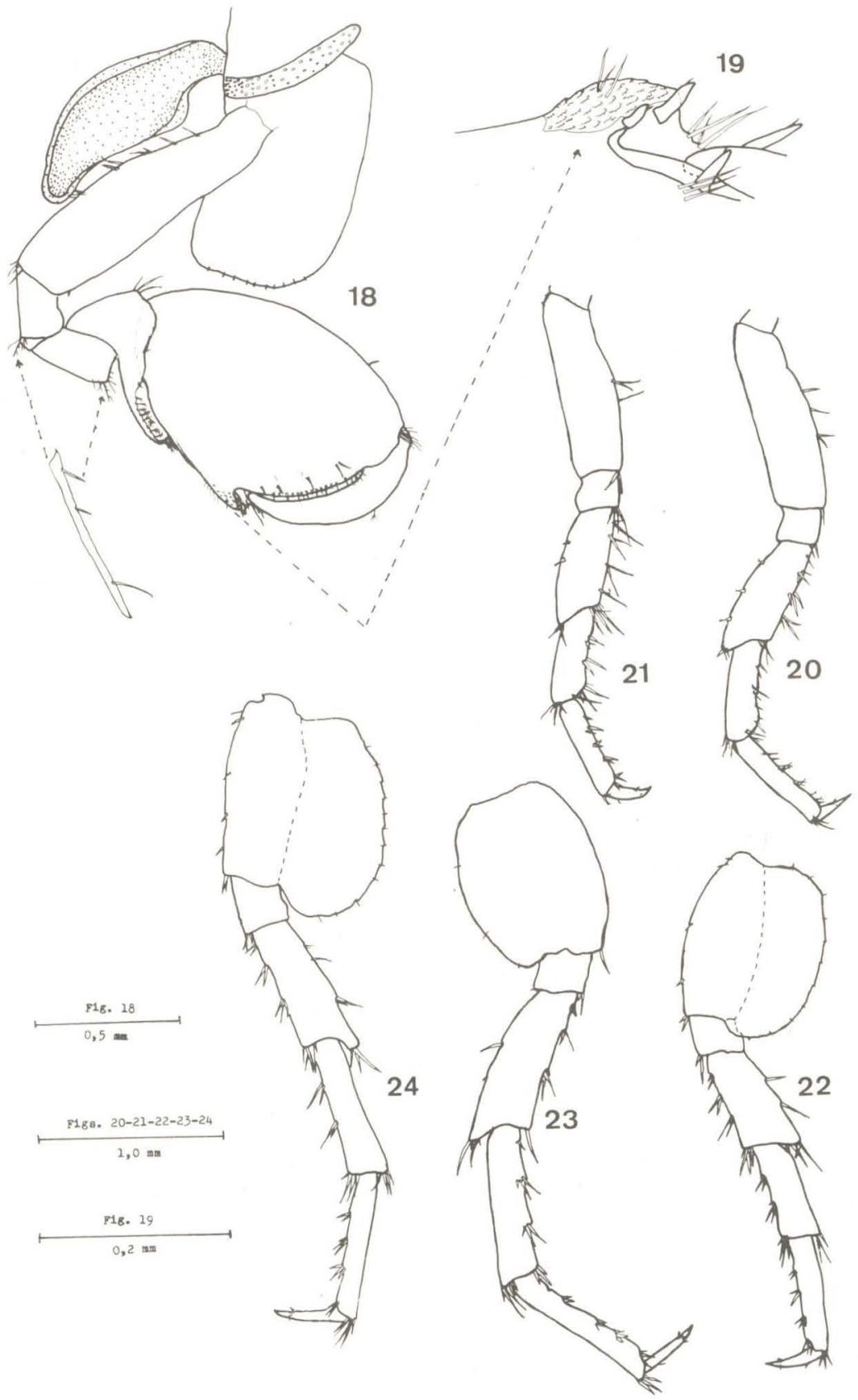

Hyalella pernix (Moreira), macho: Fig. 18 - Gnatópode 2 (lado interno); Fig. 19 - Extremidade distal da margem posterior do gnatópode 2 (lado interno); Fig. 20 - Pereópode 1; Fig. 21 - Pereópode 2; Fig. 22 - Pereópode 3; Fig. 23 - Pereópode 4; Fig. 24 - Pereópode 5. 


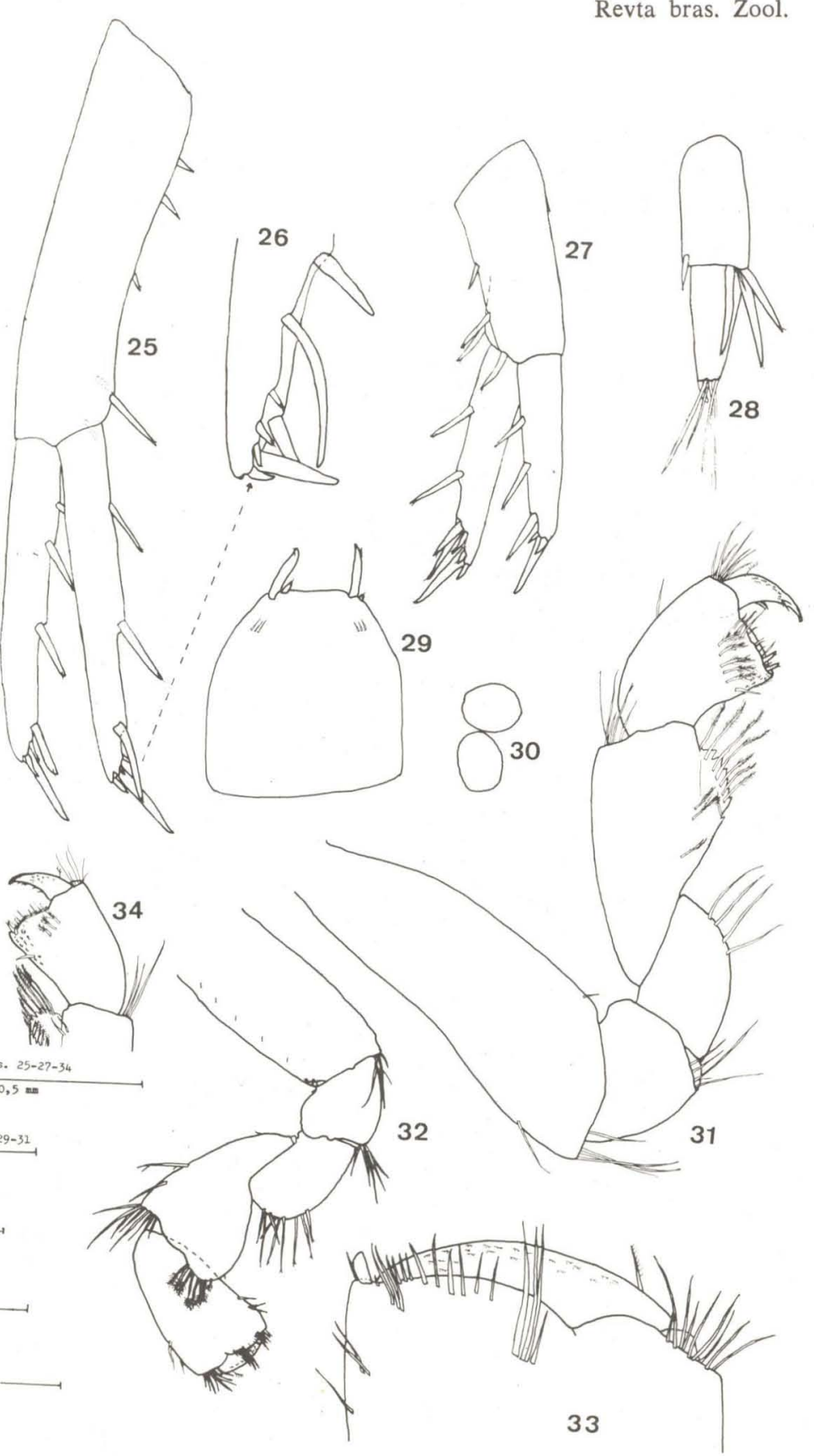

Hyalella pernix (Moreira), macho): Fig. 25 - Urópode 1; Fig. 26 - Ápice do ramo interno do urópode 1; Fig. 27 - Urópode 2; Fig. 28 - Urópode 3; Fig. 29 - Télson. Fêmea: Fig. $30-$ Ovos; Fig. $31-$ Gnatópode 1 (lado interno); Fig. 32 - Gnatópode 2 (lado externo); Fig. 33 - Dátilo e terço distal do própode do gnatópode 2 (lado externo); Fig. 34 - Dátilo, própode e terço distal do carpo do gnatópode 2 (lado interno). 


\section{REFERENCIAS}

Barnard, J. L., 1958. Index to the recent Families, Genera and Species of the Gammaridean Amphipoda (Crustacea). Occ. Pap. Allan Hancock Fdn 19: $1-145$.

Cavalieri, F., 1968. Hyalella pampeana sp. nov., una nueva especie de anfipodo de agua dulce (Gammaridea: Hyalellidae). Neotropica 14: 107-117.

Holsinger, J. R., 1981. Amphipoda: 36-40. In: S. H. Hurlbert (ed.). Aquatic Biota of Southern South America, San Diego State University, San Diego, California. 1. Arthropoda: xii $+1-323$.

Moreira, C. 1903. Uma espécie nova de amphipode orchestídeo que vive a 2.240 metros sobre o nível do mar. Archos Mus. nac., Rio de J. 12: $187-192$.

Oliveira, L. H. P., 1953. Crustacea Amphipoda do Rio de Janeiro. Mems. Inst. Oswaldo Cruz 51: 289-376.

Schellenberg, A. 1931. Gammariden und Caprelliden des Magellangebietes, Südgeorgiens uns der Westantarktis. Zool. Results Swedish Antarct. Exped. 1901-1903, 2(6): 1-290.

Schellenberg, A., 1943. Süsswasseramphipodem (Crustacea): 217-223. In: E. Titschack (ed.), Beiträge zur Fauna Perus, Hamburg 2: 200-206.

Shoemaker, C. R., 1942. A new specie of Amphipoda from Uruguay and Brazil. J. Wash. Acad. Sci. 32(3): 80-82.

Stebbing, T. R. R., 1906. Amphipoda I: Gammaridae. Das Tierreich 21: i-xxxix $+1-806,127$ text-figs. 